\title{
Imaging features in takotsubo cardiomyopathy
}

\author{
Ahmed Bashir, Neda Noroozian, Richard P Steeds, Sohail Q Khan
}

Department of Cardiology Queen Elizabeth Hospital, Birmingham, UK

\section{Correspondence to} Dr Neda Noroozian, neda_noroozian@yahoo.com

\section{DESCRIPTION}

A woman in her mid-80s presented with sudden onset severe chest pain radiating to her left shoulder. A 12-lead ECG showed anterolateral ST-segment elevation with loss of $\mathrm{R}$ waves, consistent with an acute myocardial infarction (figure 1A).

Emergency coronary angiography revealed unobstructed coronary arteries with only mild atheroma (figure 2A,B). Left ventriculography confirmed anteroapical ballooning of the left ventricle (figure 2C,D) consistent with takotsubo cardiomyopathy. Although no proximate emotional insult was evident she had recently dealt with the bereavement of a close family member.

A transthoracic echocardiogram in the coronary care unit confirmed moderately impaired left ventricular (LV) function (ejection fraction 40-45\%).
High-sensitive troponin-T peaked at $195 \mathrm{ng} / \mathrm{L}$ (normal < $14 \mathrm{ng} / \mathrm{L}$ ). Cardiac MRI revealed thinned and akinetic apical segments of the LV (figure 3A,B) making it difficult to differentiate scarred myocardium (eg, due to old myocardial infarction) from stunned myocardium secondary to takotsubo cardiomyopathy. There was no late myocardial gadolinium enhancement (figure 3C,D).

The patient made a complete functional recovery and was discharged home on no medication. On follow-up at 3 months, the patient was asymptomatic with evidence of recovery of anterior $R$ waves on ECG (figure 1B). There was complete resolution of the apical wall thinning and akinesia demonstrated on repeat cardiac MRI at 3 months (figure $4 \mathrm{~A}, \mathrm{~B}$ ) with no late myocardial gadolinium enhancement (figure 4C,D).

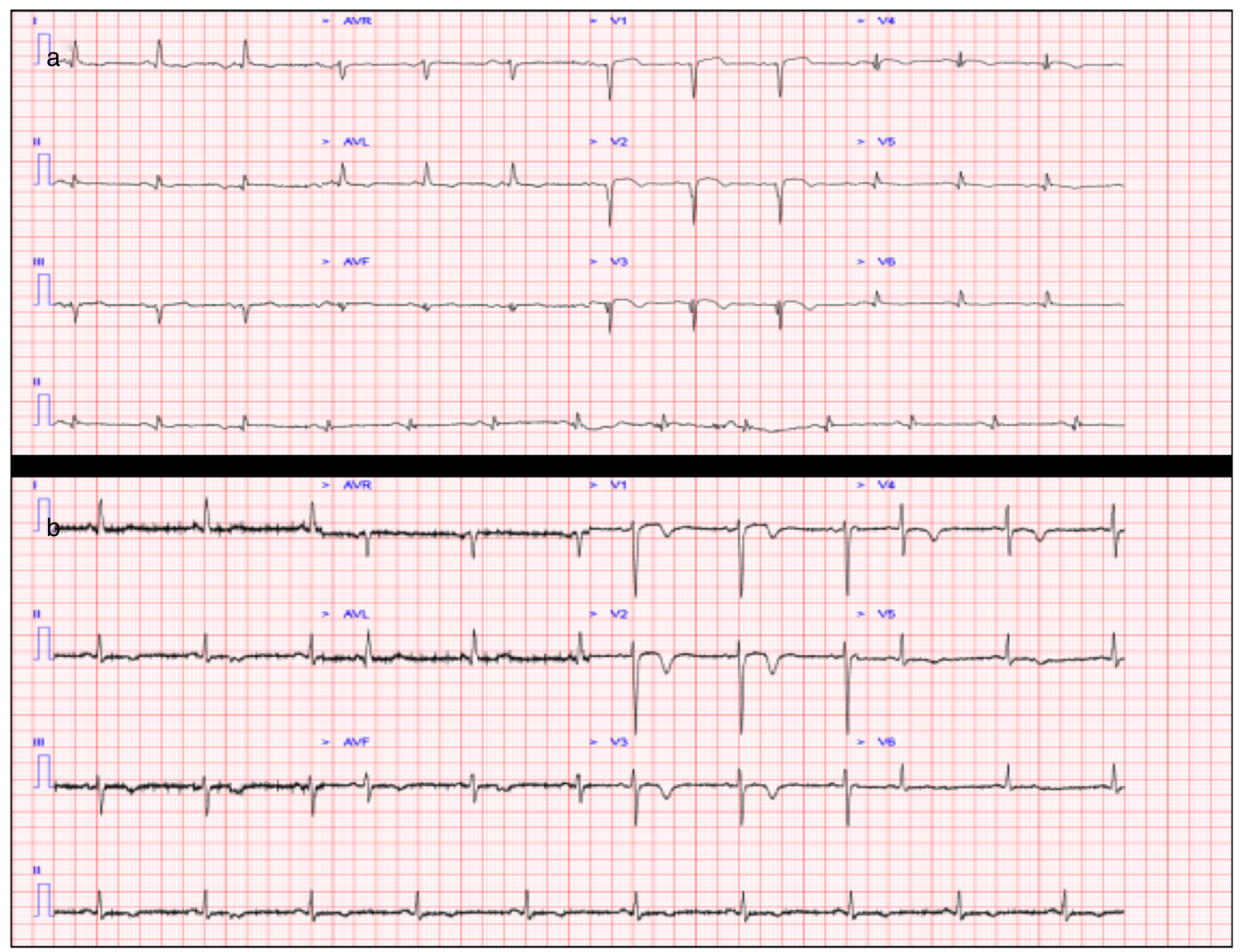

Figure 1 (A) ECG on admission showing anterolateral ST-segment elevation with loss of $R$ waves, consistent with an acute myocardial infarction. (B) ECG on follow-up at 3 months showing evidence of recovery of anterior R waves on ECG.

To cite: Bashir A, Noroozian N, Steeds RP, et al. BMJ Case Rep Published online: [please include Day Month Year] doi:10.1136/bcr-2013201394 

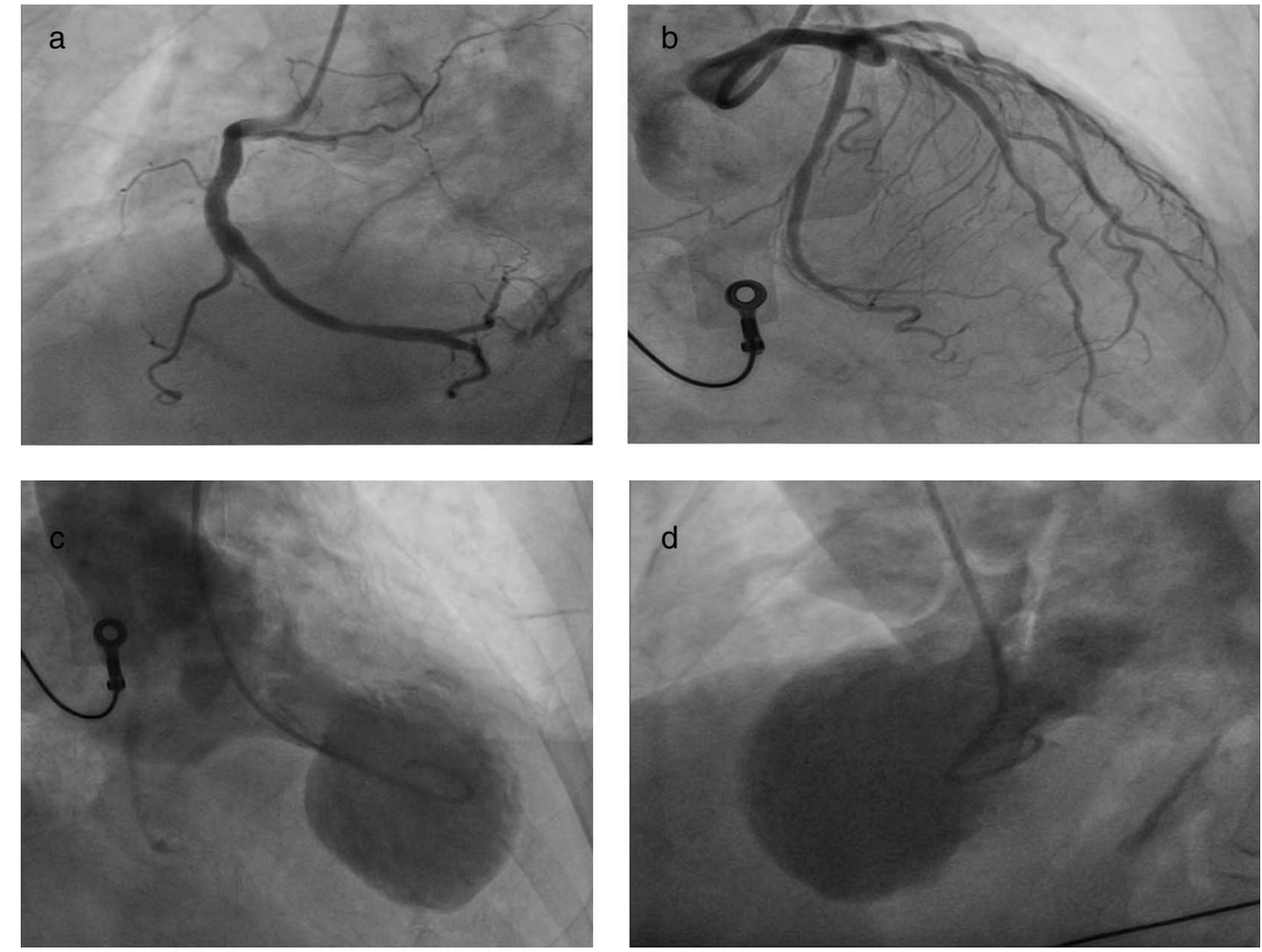

Figure 2 (A and B) Coronary angiography confirming unobstructed coronary arteries. (C and D) Left ventriculography revealed anteroapical ballooning of the left ventricle ,consistent with takotsubo cardiomyopathy.

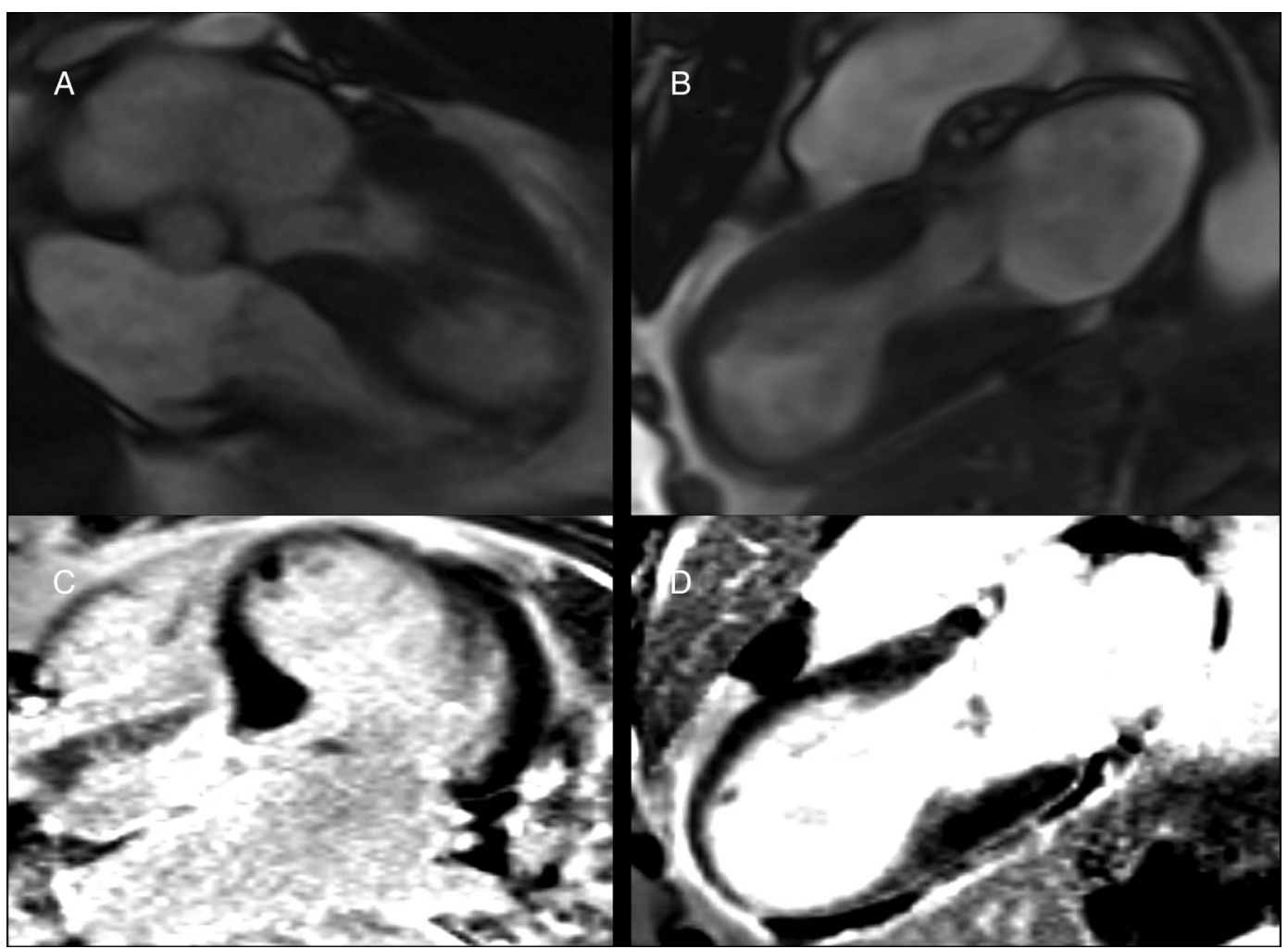

Figure 3 ( $A$ and B) Thinned and akinetic apical segments of the left ventricular. ( $C$ and $D$ ) There was no late myocardial gadolinium enhancement. 


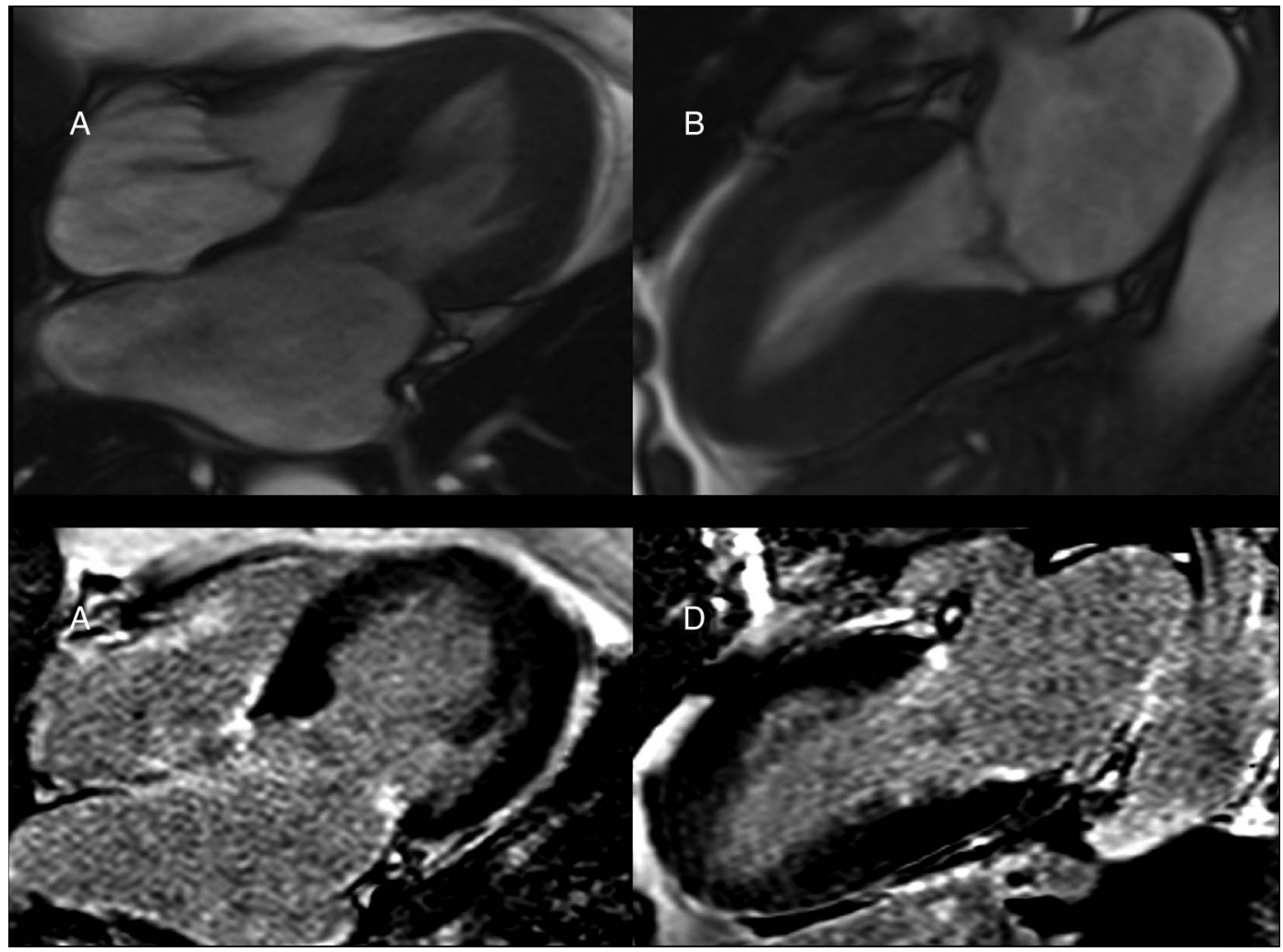

Figure 4 ( $A$ and B) Complete resolution of the apical wall thinning and akinesia. (C and D) No late myocardial gadolinium enhancement at 3 months.

\section{Learning points}

- Takotsubo cardiomyopathy (TCM) or apical ballooning syndrome is a well-recognised clinical entity. Although the pathophysiological mechanisms are not fully understood the apical ballooning that results is thought to occur due to a sudden catecholamine surge ${ }^{1}$ and acute stress has been indicated as a precipitant for the transient left ventricular apical ballooning in about a quarter of cases. ${ }^{2}$

- Comparative studies in patients with acute myocardial infarction or TCM have found cardiac MRI scanning to be a useful tool in the acute setting. Subendocardial hypoenhancement is not seen in patients with TCM as was the case in our patient. ${ }^{3}$

- The patient had dramatic myocardial thinning evident on cardiac MRI with loss of $R$ waves on her ECG making it difficult to differentiate her presentation from a previous myocardial infarction.
Contributors $A B$ was involved in the acquisition of data and analysis and drafting of the article. NN was involved in the drafting of the article. RS was involved in the acquisition of data and analysis. SQK was involved in the conception and design, revision of the article and final approval.

Competing interests None.

Patient consent Obtained.

Provenance and peer review Not commissioned; externally peer reviewed.

\section{REFERENCES}

1 Wittstein IS, Thiemann DR, Lima JA, et al. Neurohumoral features of myocardial stunning due to sudden emotional stress. N Engl I Med 2005;352:539.

2 Gianni M, Dentali F, Grandi AM, et al. Apical ballooning syndrome or Takotsubo cardiomyopathy: a systematic review. Eur Heart J 2006:27:1523-9.

3 Gerbaud E, Montaudon M, Leroux L, et al. MRI for the diagnosis of left ventricular apical ballooning syndrome (LVABS). Eur Radiol 2008:18:947-54.

Copyright 2013 BMJ Publishing Group. All rights reserved. For permission to reuse any of this content visit http://group.bmj.com/group/rights-licensing/permissions.

BMJ Case Report Fellows may re-use this article for personal use and teaching without any further permission.

Become a Fellow of BMJ Case Reports today and you can:

- Submit as many cases as you like

- Enjoy fast sympathetic peer review and rapid publication of accepted articles

- Access all the published articles

- Re-use any of the published material for personal use and teaching without further permission

For information on Institutional Fellowships contact consortiasales@bmjgroup.com

Visit casereports.bmj.com for more articles like this and to become a Fellow 